\title{
Satisfaction of Academic Specialization among Students of the Department of Educational Sciences and Its Relation to Self-Esteem
}

\author{
Mahmoud Alsalkhi \\ Assoc. Prof., Department of Educational Sciences, University of Petra, Jordan, \\ malsalkhi@yahoo.com
}

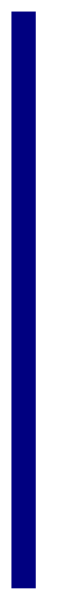

This study aimed at knowing the level of specialty satisfaction and its relation to the self- esteem of the students in the Department of Educational Sciences of the University of Petra. In order to accomplish the objective of this study, a specialty satisfaction scale was established covering 30 items. Also, Rosenberg scale of 10 items was used to measure self-esteem. Both scales were applied on a study sample of 182 female students. The study results showed a high level of female students' satisfaction with their academic specialty. In addition, statistical indicative differences were observed in the satisfaction levels due to the specialty variable and in the interest of the child education specialty. Also, similar differences were shown attributed to the GPA of the scale points and in the interest of the excellent average. However, the study results showed no statistical indicative differences in the satisfaction level due to the academic level variable. Additionally, the students in the Department of Educational Sciences have positive levels above average on the scale of self-esteem, and the results showed the existence of the positive relation between specialty satisfaction level and self- esteem.

Keywords: specialty satisfaction, self -esteem, department of educational sciences, academic specialization, student

\section{INTRODUCTION}

The success of the students depends on their right selection of the specialty appropriate to their interests and competencies. This success is closely connected to their success in the future career. If the selection of specialty was suitable to the students' interests and capabilities, they will excel in their career and become an expert in their field specialty (Alwan, 2007).

The student's selection of their specialty is influenced by many interactive factors. For example, some students choose their areas of specialty based on financial considerations such as educational expenses and the expected return benefits. Also, the selection of specialty may be influenced by social and psychological factors such as the existence of a special academic program, the availability of a comfortable academic environment and

Citation: Alsalkhi, M. (2018). Satisfaction of Academic Specialization among Students of the Department of Educational Sciences and Its Relation to Self-Esteem. International Journal of Instruction, 11(4), 107-122. https://doi.org/10.12973/iji.2018.1148a 
the university location. Other factors may include the guidance and orientation given to the students at school by teachers or academic advisors. Also, the selection may be affected by advice from parents, friends, and classmates. Finally, the selection is determined by the ability of the student to meet the admission requirements of a certain specialty or college (Mcdonough, 1994).

The decision of selecting a specialty is one of the most important decisions taken in one's life as it determines his future. Mature people choose the specialty that fulfills the future life requirements and keeps in line with the social, economic, and technological developments. The specialty selection is considered as an individual as well as a social issue. At the individual level, it determines basic issues in one's life, and at the social level, it helps the person to get a secured job and progress to a higher position (Williams, 2007).

The majority of high school graduates face difficulty in selecting a suitable and promising specialty which qualifies them for the future career. The selection of an inappropriate specialty will, no doubt, result in dissatisfaction with the future career (Zhang, 2007).

It is of note that the University of Petra in Jordan offers 28 undergraduate specialties for students to select the specialty that suits their interests, competencies and the needs of the society. The specialty of educational sciences is one of those available at University of Petra. Unfortunately, this specialty lacks the motivation of students to choose in the absence of its social prestige, low salaries, and limited opportunities for job advancement.

\section{Specialty Satisfaction}

Specialty satisfaction is considered as an important issue as it makes students feel comfortable and motivated to accomplish success and avoid failure. In addition, this satisfaction provides students with internal feeling manifested by their behavior that expresses their comfort with specialty and university (Meesa, 2014).

The specialty satisfaction can be defined as the extent of meeting the student's basic and secondary needs through studying his specialty and later working in the future career. Also, the specialty satisfaction has an important role in accomplishing the university aims. The selection of a specialty will influence the personal and social levels as well as his academic results and future career (Awad \& Ali, 2001).

The Social Professional Knowledge Theory (Lent, et al, 1994) is considered as the most important theory which explained the specialty satisfaction. This theory confirmed the existence of the following three factors that affect the specialty satisfaction:

- Development in accomplishing the desired objectives.

- Selection.

- Performance.

Lent (2004) confirmed that some social knowledge changes such as self- esteem may be beneficial in studying the specialty satisfaction. Also, Lent confirmed that self- esteem 
and the ability to develop the accomplishment of aims indicate student's satisfaction in his academic life.

\section{Self Esteem}

The self-development indicates the individual's judgment on the importance of his personality. For example, people with high self- esteem believe that they are valuable and important. and, therefore, they deserve others' respect and appreciation. They also have confidence in the validity of their thoughts. On the other hand, people with low self- esteem do not see any value or importance of themselves, and they believe of being unaccepted by others and have the feeling of being incapable of making the positive contribution (Deeb, 2014).

Self- esteem is an expression of value, confidence, or love, and these are basic elements required to achieve psychological balance and feeling with self-satisfaction. It is a selfjudgment that determines the extent of the psychological balance achievement. If the balance is positive, it gives the individual the ability to perform proper reactions and a feeling of happiness. This provides one's self ability to face the life difficulties. But negative balance leads to pessimism and lack of confidence which hinders communication with others and adaptation with events, and this will negatively affect the psychological health (Alawi, 2014). Also, self- esteem contributes in determining the individual's behavior, motivation, and persistence on performing a specific task (AlUlwan, 2015).

Murk (1999) believes that self- esteem has two degrees: high degree which creates positive behavior that helps them assess others positively and determine their attitudes accepted to them. On the other hand, the low degree of self- esteem that creates internal threats and permanent condition of negative feeling that causes isolation and lack of security.

The current study was based on theories that explained self- esteem such as Walz theory (1991), Cooper Smith theory(1976), and Rozenberg theory(1965). This study aimed at studying the growth and development of the psychological self-behavior taking into consideration the social norms. Also, the study emphasized the adolescence group pertaining to the development of their positive self-behavior with special emphasis on the family role in supporting or ignoring this behavior.

\section{Review of Literature}

Hasan (2016) conducted a study aimed at finding the self- esteem level of the students in the Education College at Al-Sudan University for Technology Sciences, and the relation of this level with anxiety. The study sample consisted of 305 male and female students, and the results reported that the self- esteem level of students was average and has no relation to anxiety.

Hanny (2015) investigated the relation between the life quality and the academic specialty satisfaction of the university students, and its relation to the gender. This study covered 100 male and female students (who were about to graduate) at the University of Hammo Green Valley. The study results showed no statistical indicative relation 
between life quality and the academic specialty satisfaction of the university students. Also, the results showed no statistical indicative differences between male and female students related to the specialty satisfaction regardless of their university specialty.

Meesa(2014) studied the relation between the academic specialty satisfaction and the ambition level of $1^{\text {st }}$ - year university students. The study was applied on a sample of 89 male and female students. The study results showed no statistical indicative differences between male and female students regarding the specialty satisfaction and ambition level. However; the study claims that there were statistical indicative differences have been detected among Arts, Science and Arabic Literature students at the aforementioned university.

Jassim and Heliw (2014) examined the relation between specialty desire and learning motivation. The study sample consisted of 160 male and female students from Baghdad University. The study results revealed that the university students exposed both specialty desire and learning motivation, and no variations were detected among different academic specialties"

Al-Amrat and Al-rfou' (2014) measured the satisfaction level of the university life and its relation to the self-esteem of the female students at Al-Tafila University in Jordan. The study sample was consisted of 302 female students selected randomly. The study results revealed an average degree of students' satisfaction with the university life, but their self-esteem scored high degree. Also, the results revealed the existence of statistical indicative variations among the satisfaction levels of the sample students regarding the university life. These differences are attributed to the specialty variable, university dormitory, and the GPA which was in favor of those students of humanity colleges and live in the dormitory, and whose GPA is either good or better. Additionally, the study results showed a connection between the satisfaction of the university life and self- esteem.

Khaza'leh and Tashtoush (2011) explored the attitudes of the special education students at Al-Qaseem University in Saudi Arabia toward their academic specialty. The study sample covered 246 male and female students. The study sample showed positive attitudes of students toward their specialties. Also, the results of this study showed no statistical indicative differences attributed to the students' academic achievement variable.

Abu Mustafa (2008) studied the attitudes of the "Psychological Guidance" students at Al-Aqsa University toward their areas of specialty. The study sample covered 240 male and female students. The study results showed positive attitudes of students toward their specialties. Also, the study showed no statistical indicative differences attributed to the students' gender and GPA variables. However, it showed the existence of differences attributed to the academic achievement variable, and in favor of the $2^{\text {nd }}$ year students.

Al-Jarrah (2007) investigated the attitudes of the Psychological Guidance students at AlYarmouk University in Jordan toward their areas of specialty, and see if there are any differences of their attitudes due to the gender, academic level, and living place variables. Also, the study aimed at finding out the nature of the relation between the 
student's GPA and his attitude toward his specialty. The study sample covered 241 male and female students. In general, the results showed a generally positive attitude of students toward their areas of specialty, whereas it showed neutral attitudes toward their teachers of the psychological guidance and toward the study plan. Furthermore, the results showed an evidence of a negative relationship between the student's academic achievement and the attitude toward his/specialty. However, it showed a positive relationship between the students' GPA and the attitude toward his specialty.

Miskiniene and Rodzeviciute (2005) studied the factors that direct students choose the teaching career. The results revealed that the most important motivation is the desire to learn and his scholastic activities which attract him to the teaching career. It should be noted that school has a fundamental role in directing the individual to take the right decision regarding his choice of the future career. The choice should be based on an objective evaluation of the career, as well as full understanding of the mental qualifications, competencies, and interest required by the target career.

Kazem and Al-Mia'mari (2004) studied the nature of the students' attitudes toward Psychology at Sultan Qabous University in Oman. In order to accomplish this objective, surveys of 58 items were applied on a sample of 260 of male and female students. The study sample showed a generally positive attitude toward Psychology, and no differences were observed that might be associated with the gender, specialty, and GPA variables.

Zayed (2004) studied the level of self-esteem of students in the Physical Education Division of Qabous University in Oman, and its relation to the academic achievement. The study sample consisted of 102 male and female students, and the results revealed a positive level of self-esteem. Also, it showed the existence of a statistical indicative relation between self-esteem level of students and their academic achievement.

Coffman and Gillgan (2003) confirmed the relationship between the social support and self-esteem, life satisfaction and its pressure. The study sample was formed of $911^{\text {st }}$ year university students. The study results showed that students who reported high social support and self-esteem levels have experienced low levels of pressure.

Al-Nabhan (2001) developed a tool to measure the study satisfaction of students in the Educational Sciences College at Mo'ata University in Jordan and its relation to the gender and primary stage variables. The study sample covered 489 male and female students, and the study tool was made of 33 items. The study results revealed an average level of study satisfaction and showed no connection with the gender and primary stage variables.

Wildman and Torres (2001) studied the factors that affect the selection of agriculture specialty by the United States students in the New Mexico University. The study sample consisted of 335 male and female students from the College of Agriculture $53.09 \%$ males and $45.2 \%$ females). The age of participants was in the range of 18-38 years and with an average of 22 years. The study results showed that the previous experience of the specialty, the knowledge of friends, and the interest of students in a field job rather than an office job were the most effective factors that impact the selection of the agriculture specialty. 
It is worth noting that studying the students' satisfaction of the academic specialty has become a critical necessity, as it is considered one of the major factors that determine the professional direction of the individual future career. Unfortunately, there are only a few studies reported in the literature regarding the satisfaction of students with the specialty of educational sciences such as class teacher and child education. For this reason, the researcher was motivated to conduct a research and analysis of this subject.

\section{Study problems \& Questions}

Specialty satisfaction may be due to reasons attributed to the student himself such as dissatisfaction of his future career, intellectual ability, academic achievement level, and the ability of the study to meet the needs of the individual. The dissatisfaction might be connected with the social and academic environment of the educational institute such as teaching methods and faculty qualifications.

It should be noted that the teacher has a very important role in shaping the behavior and ideas of his students who acquire their principles and values from their social as well as the academic environment. Therefore, the teacher should be a good example for his students in order to lead them in the right direction and develop their personalities.

The researcher, through his work as a faculty member and a supervisor of the field training in the Educational Sciences Division (ESD) at University of Petra, observed that a number of female students showed the low level of satisfaction with their specialty. This was a motivation for the researcher to study the specialty satisfaction level and its relation to the degree of self- esteem of the female students in the ESD. More precisely, the study tried to answer the following questions:

1- What is the specialty satisfaction level of students in the ESD at the University of Petra?

2- Does the specialty satisfaction level of students in the ESD differ according to the specialty (Class Teacher, Child Education), GPA, and academic level?

3- What is the level of self-esteem of female students in the ESD?

4- Is there any relation between the specialty satisfaction level and self-esteem of the students in the ESD?

\section{Importance of Study}

The importance of the current study is implied in understanding the concept of selfesteem that receives special attention of Psychology scientists and being considered as a positive concept in Psychology science. Also, the importance of this study is due to the fact that self-esteem may reflect the psychological case of the university student. In addition, the study is considered important as it highlights the concept of the academic specialty satisfaction of the students at the University of Petra that has a direct impact on their achievement and professional future directions.

\section{Study Purposes}

The current study is aiming at realizing the following:

1- The specialty satisfaction level of students in ESD at the University of Petra.

2- The relation between the specialty satisfaction level and self-esteem. 
3- Recognizing the level of self-esteem of students in ESD at the University of Petra.

4- Statistical indicative differences in the specialty satisfaction level of students in the ESD pertaining to variables of specialty, GPA, and academic level.

\section{Study Limitation}

The current study is limited to the female students in the Educational Sciences Division of the University of Petra, Jordan for the 2016/2017 scholastic year. This explains the emphasis of the study on female participants as shown later.

\section{METHOD}

\section{Study Procedure}

This study followed a correlative and Descriptive Approach to explore the specialty satisfaction level of the students in the Educational Sciences Division of the University of Petra. Also, the same procedure is applied in understanding the effect of specialty satisfaction by the specialty, GPA, and academic levels.

\section{Participants}

The study population consisted of 409 female students registered in the Educational Sciences Division at the University of Petra for the $2^{\text {nd }}$ semester of the academic year 2016/2017. The study population includes 233 female students specialize in the class teacher, and 176 female students selected the specialty of child education. Whereas, the study sample consisted of 182 female students selected randomly, of which 111 female students choose the Class Teacher specialty, while 71 female students choose the Child Education specialty.

Table 1

Number and percentage of the sample

\begin{tabular}{llll}
\hline Variable & \multicolumn{1}{c}{ Levels } & Frequency & Percentage \\
\hline Specialty & Class Teacher & 111 & 60.99 \\
& Child Education & 71 & 39.01 \\
& Total & 182 & 100.0 \\
\hline GPA & Excellent & 10 & 5.50 \\
& V. good & 47 & 25.82 \\
& Good & 71 & 39.01 \\
& Fair & 40 & 21.97 \\
& Weak & 14 & 7.70 \\
& Total & 182 & 100.0 \\
\hline Academic Level & $1^{\text {st }}$ year & 28 & 15.38 \\
& $2^{\text {nd }}$ year & 39 & 21.43 \\
& $3^{\text {rd }}$ year & 56 & 30.77 \\
& $4^{\text {th }}$ year & 59 & 32.42 \\
& Total & 182 & 100.0 \\
\hline
\end{tabular}




\section{Study Tools}

\section{First: Specialty Satisfaction Measure:}

The researcher developed a tool to measure the specialty satisfaction of the students in the Educational Sciences Division (ESD) at University of Petra based on previous studies and the educational literature related to the specialty satisfaction. The measure tool is made of 35 items. In order to answer these items, the sample participants were requested to determine their agreement degree on each item using the five-measure scale of Likert. The items were given five options: strongly agree (5), agree (4), neutral (3), disagree (2), and strongly disagree (1).

In order to ensure the credibility of the content of specialty satisfaction measure, it was reviewed by a group of arbitrators who specialist of the Education Curricula and Psychology Science. Their role was to study the measure tool, and give their opinions regarding the suitability of the item to the content and the adequacy of the tool as related to the number of items, and its coverage and variety. Also, the group was requested to give any notes or comments pertaining to the modification, deletion or changes of the tool. Each item was accredited if it won $85 \%$ votes of the arbitrators. As a result of the review, five items were deleted, and 30 items were recommended for the tool.

The following gradual statistics was used to distribute the Arithmetic Averages of the measurement items into three levels using a range of five degrees:

- Low level (1-2.33) degree

- Average level (2.34-3.67) degree

- High level (3.68-5.00) degree

In order to ensure the consistency of the measurement, it was applied to a sample, outside the study sample, consisted of 28 male and female students from Isra' University, Jordan. After that, the measure was reapplied on the same sample after two weeks using the Test \& Re-test method. The consistency coefficient was calculated using Cronbach Alfa formula, and its value was found 0.928.

\section{Second: Rozenberg Measure For Self- Assessment}

This measure is considered as one of the most known measures of self-esteem worldwide. The measure is made of ten expressions of gradual scale according to Likart: strongly agree, agree, disagree, and strongly disagree. The measure contains five positive expressions that carry the numbers $1,3,4,6,9$. Also, the measure contains five negative expressions carrying the numbers $2,5,7,8,10$. The degrees were calculated according to the Fourth-graduation Ladder $(0,1,2,3)$ for positive expressions, and ( 3 , $2,1,0)$ for negative expressions.

In order to confirm the credibility of the measure, the researcher asked a group of arbitrators to review the measure and give their feedback regarding its suitability to the measure self-esteem. As a result of the review, $91 \%$ of the group recommended its suitability. 
The researcher calculated the consistency coefficient by reapplying it on the aforementioned group, and the reported coefficient was 0.936 .

\section{Study Design}

The study involved the following variables:

First: Independent Variables that involved:

- Specialty: contains Class Teacher and Child Education

- GPA: has five levels: Excellent, Very Good, Good, Fair, Weak

- Academic Level: has four levels: $1^{\text {st }}$ Year, $2^{\text {nd }}$ Year, $3^{\text {rd }}$ Year, $4^{\text {th }}$ Year

\section{Second: Dependent Variables that involved}

- Specialty Satisfaction

- Self-Esteem

\section{Data Analysis}

The Statistical Package for Social Sciences (SPSS) was applied to analyse the study results using the following statistical treatments:

- Cronbach Alfa Formula to calculate the consistency of study tools.

- Arithmetic Averages and Standard Deviations

- Independent T test; " $T$ " Test to explore any indicative differences of responses given by students of University of Petra regarding the specialty satisfaction attributed to study variables.

- Test of individual differences, and Pearson coefficient to reveal the relation between the specialty satisfaction level and self-esteem of the study sample participants.

\section{FINDINGS AND DISCUSSION}

To answer the $1^{\text {st }}$ question; "What is the specialty satisfaction level of students in the ESD at the University of Petra?" The percent of specialty satisfaction of the female students was calculated as shown in the next table.

Table 2

The percent of specialty satisfaction of female students in the ESD

\begin{tabular}{|c|c|c|c|c|c|c|c|c|c|}
\hline Scale & $\mathrm{N}$ & M & S.D & $\begin{array}{l}\text { N. of students } \\
\text { (HLSS)* }\end{array}$ & $\%$ & $\begin{array}{l}\text { N. of } \\
\text { students } \\
\text { (AS)** }\end{array}$ & $\%$ & $\begin{array}{l}\text { N. of } \\
\text { students } \\
\text { (LS)*** }\end{array}$ & $\%$ \\
\hline $\begin{array}{l}\text { specialty } \\
\text { satisfaction }\end{array}$ & 182 & 3.762 & 0.5699 & 109 & 59.89 & 68 & 37.36 & 5 & 2.75 \\
\hline
\end{tabular}

\footnotetext{
* High Level of Specialty Satisfaction

** Average Satisfaction

*** Low Satisfaction
}

It is observed from the above table that 109 female students $(59.89 \%)$ showed high satisfaction, and 68 students $(37.36 \%)$ showed average satisfaction. Whereas, only 5 students $(2.75 \%)$ showed low satisfaction. This confirms that the majority of surveyed female students showed a high level of specialty satisfaction. 
The Arithmetic Average of the study sample on the specialty satisfaction scale is (3.762) and the Standard Deviation is (0.5699). Upon applying the " $T$ " test on a study sample, it was found that the value $\left(\mathrm{t}_{(182)}=89.05, \mathrm{p}<.001\right)$ showed a statistical significant differences. In general, the study result indicated that the female students in the ESD were more satisfied with their study specialty.

Table 3

The " $T$ " test results of one sample of the female students in the ESD on the specialty satisfaction scale

\begin{tabular}{lllllll}
\hline Variable & $\mathrm{N}$ & $* \mathrm{M}$ & $\mathrm{S} . \mathrm{D}$ & $\mathrm{T}$ & $\mathrm{D} . \mathrm{F}$ & Sig \\
\hline $\begin{array}{l}\text { specialty } \\
\text { satisfaction }\end{array}$ & 182 & 3.762 & 0.5699 & 89.05 & 181 & $0.000 * *$
\end{tabular}

*Mean

** Statistical indication

This result can be attributed to the specialty satisfaction of the female students, and to their ability to determine their future career. Also, the result is due to the students' belief in their capabilities, in addition to the ability of the EDS to accomplish the objectives of students by using modern teaching methods, various evaluation tools, and developed teaching aids.

The above result agrees with the studies of Al-Jarrah (2007) and Jassim and Heliw (2014).which both showed the high degree of students' satisfaction with their academic specialty. But the result differs, however, with the study of AL- Nabhan (2001) which showed the low degree of study satisfaction.

To answer the $2^{\text {nd }}$ question: Does the specialty satisfaction level of students in the ESD differ according to the specialty (Class Teacher, Child Education), GPA, and academic level?

Following is a presentation of the $2^{\text {nd }}$ question results:

\section{Results pertaining to study specialty variable}

The " $T$ " test was applied on the independent samples to test the indicative differences in the estimates of the female students in ESD related to the specialty satisfaction level in view of the academic specialty variable (class teacher, child education). The results are given below.

Table 4

Mean - standard deviation and statistical significant differences' between two specialties (Class Teacher and Child Education)

\begin{tabular}{lllllll}
\hline Specialty & $\mathrm{N}$ & $\mathrm{M}$ & $\mathrm{S} . \mathrm{D}$ & $\mathrm{T}$ & $\mathrm{D} . \mathrm{F}$ & Sig \\
\hline Class Teacher & 111 & 3.689 & .5637 & -2.180 & 180 & $0.031^{*}$ \\
Child Education & 71 & 3.876 & .5647 & & & \\
\hline
\end{tabular}

*Statistical indication

The above results indicate the existence of statistical indicative differences in the level of the specialty satisfaction in view of specialty variable. This result is supported by the " $T$ " value of $(-2.180)$ that is considered as a statistical indicative value at an indication level of $(\alpha=0.05)$, and this result was in favor of students in the child education 
specialty. Also, the result was supported by the Arithmetic Average (3.876) of Students' estimates, which is higher than the Arithmetic Average (3.689) of students in the class teacher specialty.

It is clear from the above results that female students specializing in child education are more satisfied with their specialty than those of class teacher specialty. This attitude may be attributed to the belief of students that the child education satisfies their goals in studying, graduation, and getting a job with a good social status. Also, they believe that this specialty is more requested in the local market than the class teacher specialty. In addition, students feel that child education specialty is less demanding and difficulty than the specialty of the class teacher. This explains that a small number of students change their specialty from child education to class teacher after the first year of study.

This result differs with the results of the studies of Jassim and Heliw (2014), Kazem and Al-Mia'mari (2004), which revealed no differences in the level of satisfaction with specialization according to the variable of specialization.

\section{Results pertaining to GPA variable}

As shown in the following table, the Arithmetic Averages and Standard Deviations were calculated to test the indicative differences in the estimates of the female students in the ESD related to the specialty satisfaction level in view of the GPA variable (excellent, very good, good, fair, weak) variable. The results revealed that.

Table 5

The Arithmetic Averages and Standard Deviations of the ESD students" estimate related to the specialty satisfaction in view of GPA variable.

\begin{tabular}{lllllll}
\hline GPA Statistics & Excellent & V.good & Good & Fair & Weak & Total \\
\hline $\mathrm{N}$ & 10 & 47 & 71 & 40 & 14 & 182 \\
$\mathrm{M}$ & 4.090 & 3.976 & 3.730 & 3.550 & 3.571 & 3.783 \\
$\mathrm{~S}$.D & 0.6511 & 0.4645 & 0.4894 & 0.7083 & 0.4888 & 0.5604 \\
\hline
\end{tabular}

The Arithmetic Averages indicate the existence of apparent differences in the estimates of ESD female students related to the specialty satisfaction in view of the GPA variable. In order to know whether or not these differences are indicative, the test of single difference analysis (One Way ANOVA) test was performed.

The results of the One way ANOVA analysis revealed statistical significant differences $\left(\mathrm{F}_{(4,181)}=4.66, \mathrm{p}<.01\right)$ in the ESD students' estimates of specialty satisfaction in view of GPA variable (Table 6).

Table 6

Means, Standard deviation and statistical significant differences among. GPA variable.

\begin{tabular}{lccccc}
\hline Source & S.S & D.F & M.S & F & Sig \\
\hline Between Groups & 0.560 & 4 & 1.401 & 4.661 & $* .001$ \\
Within Groups & 53.192 & 177 & 0.301 & & \\
Total & 58.795 & 181 & & & \\
& & & & &
\end{tabular}

*Statistical indication

It is clear from the above table, the existence of statistical indicative differences in the specialty satisfaction level according to the GPA in favor of "excellent" average with an 
Arithmetic Average of (4.090). This means that students with an excellent average show a specialty satisfaction level higher than other GPAs. This confirms the high desire and interest of students in their specialty which reflected positively on their academic achievement. The "excellent" students may have high competences that motivate them to excel in their specialty and appreciate the value and importance of the future teaching career.

This result is consistent with what Al-jarrah came into in his study (2007). His results have shown that there are differences among students' specialty satisfaction level based on their GPA. On the other hand, Khaza'leh and Tachtoush (2011), .Abu Mustafa (2008),Kazem and Al-Mia'mari studies have not depicted any of these differences.

\section{Results pertaining to academic level variable}

As shown in the following table, the Arithmetic Averages and Standard Deviations were calculated to test the indicative differences in the estimates of the ESD female students related to the specialty satisfaction level in view of the academic level variable $\left(1^{\text {st }}\right.$ year, $2^{\text {nd }}$ year, $3^{\text {rd }}$ year, $4^{\text {th }}$ year). The results are given below.

\section{Table 7}

The Arithmetic Averages and Standard Deviations of the ESD students" estimate related to the specialty satisfaction in view of academic Level variable.

\begin{tabular}{llllll} 
Academic Level & $1^{\text {st }}$ year & $2^{\text {nd }}$ year & $3^{\text {rd }}$ year & $4^{\text {th }}$ year & Total \\
Statistics & 28 & 39 & 56 & 59 & 182 \\
$\mathrm{~N}$ & 28 & 3.636 & 3.814 & 3.693 & \\
$\mathrm{M}$ & 3.977 & & & & \\
S.D & 0.4653 & 0.6050 & 0.5639 & 0.5753 & \\
& & & & & \\
\hline
\end{tabular}

The above Arithmetic Averages indicate the existence of apparent differences in the estimates of ESD female students related to the specialty satisfaction in view of the academic level variable. In order to know if these differences are indicative, the test of single difference analysis (One Way ANOVA) test was performed. The results are shown below:

The results of One way ANOVA analysis revealed that there were not important differences in the ESD students' estimates of specialty satisfaction in view of the academic level variable $\left(\mathrm{F}_{(3,181)}=2.46, \mathrm{p}>.05\right)$.

Table 8

Means, Standard deviation and statistical significant differences among academic level variable.

\begin{tabular}{llllll}
\hline Source & S.S & D.F & M.S & F & Sig \\
\hline Between Groups & 2.343 & 3 & & & $* .781$ \\
Within Groups & 56.452 & 178 & 0.317 & & \\
Total & 58.795 & 181 & & & \\
& & & & & \\
\hline
\end{tabular}

* Statistical indication 
The above table shows the non-existence of statistical indicative differences in the specialty satisfaction level according to the academic level. The researcher attributed this result to the similarity of the academic environment of all study stages, and the existence of common courses between the academic levels. Also, the result is due to other factors such as the common extracurricular activities which impact the specialty satisfaction and the similarity of teaching methods, evaluation, and communication of teachers with their students.

This result is totally different from Abu Mustafa (2008) and Al-jarrah (2007) studies respectively. Their studies have shown some differences in specialty satisfaction level based on the students' academic level.

In order to answer the $3^{\text {rd }}$ question "What is the level of self-esteem of female students in the ESD?", the Arithmetic Averages and Standard Deviations were used as in the following table:

Table 9

The arithmetic averages and standard deviations of self-esteem items.

\begin{tabular}{clcc}
\hline No. & \multicolumn{1}{c}{ ITEM } & $\begin{array}{c}\text { Arithmetic } \\
\text { Average }\end{array}$ & S.D \\
\hline 1 & My personality has a value like other people & 2.483 & 0.6541 \\
2 & Frequently, I feel that I am an unsuccessful person & 2.302 & 0.8289 \\
3 & I have many merits that make me proud of myself & 2.450 & 0.6176 \\
4 & I have the ability to accomplish work with high quality & 2.324 & 0.6388 \\
5 & I have nothing that deserves my pride & 2.307 & 0.7952 \\
6 & My idea of myself is positive in general & 2.385 & 0.6774 \\
7 & I feel that my personality is absolutely worthless & 2.505 & 0.7263 \\
8 & I hope I have more respect for myself & 1.258 & 1.005 \\
9 & I am quite satisfied with myself & 2.472 & 0.6867 \\
10 & I feel that I have self-esteem less than others & 2.313 & 0.8704 \\
\hline & & 22.798 & 0.4760 \\
\hline
\end{tabular}

It is clear from the above table that the female students in the ESD at the University of Petra have above average positive levels on the self-esteem measure. The overall Arithmetic Average of the study sample students was (22.798) and the Standard Deviation was (0.4260). This average is higher than the theoretical average of (15). This result is attributed to the academic environment of the Educational Scientific Division that enjoys the support and guidance in addition to the social and psychological support of the faculty and management.

This result agrees with AL-Aamarat and AL-rfou' results (2014) which shows the high level of self-esteem among students. However, it differs from Hasan's results (2016) which proved average levels of self-esteem.

In order to answer the $4^{\text {th }}$ question "Is there any relation between the specialty satisfaction level and self-esteem of the students in the ESD?", Person connection coefficient was used as illustrated in the following table: 
Table 10

Pearson correlations coefficients for each factor of the two questionnaires

\begin{tabular}{lcll}
\hline Variables & \multicolumn{3}{c}{ Self-Esteem } \\
\hline Specialty Satisfaction & $\mathrm{N}$ & $\begin{array}{l}\text { Correlation } \\
\text { Coefficient }\end{array}$ & Sig \\
& 182 & 0.505 & $0.010^{*}$
\end{tabular}

* Statistical Indication at level $(\alpha=0.01)$

It is clear from the above results that there is a positive connection relation and a statistical indication of specialty satisfaction and self-esteem of ESD female students. This means that the differences between students' degrees in the specialty satisfaction level are explained by the differences between their degrees in the self-esteem level and vice versa. We can conclude that the two relations are connected together, and one relation can be explained by the other.

\section{CONCLUSION}

This research study focused on four variables including study specialty, academic performance (GPA), academic level, and self-esteem. The research results indicated statistical differences between the specialty satisfaction level and the study specialty variable in favor of child education. It is of note that high specialty satisfaction level provides students with a comfortable learning environment and thus helps them to excel in their academic performance and achieve a high GPA. This confirms a positive relationship between specialty satisfaction and academic performance variables. In addition, the study results indicated non-existence of statistical differences between the specialty satisfaction level and the academic level. This result may be attributed to the similarity of the academic environments of all study stages, and the existence of common courses between the academic levels. Finally, the research results showed a positive relation between the specialty satisfaction and self-esteem variables. This means that specialty satisfaction increases with the improvement of self-esteem level and vice versa. In general, the majority of surveyed participants demonstrated a high level of specialty satisfaction.

\section{RECOMMENDATIONS}

In view of the study results, the researcher recommends the following: Arranging an orientation program for interested High School graduates to brief them on the available study specialties in the University, and the prospective jobs in the market; reviewing the factors that may influence the specialty satisfaction with the new students in order to help them select the most appropriate study specialty; extending this research to include other factors that may influence the specialty satisfaction such as student-teacher relationship, social prestige of future career and forcing sponsored students to accept a specialty assigned by the sponsor. 


\section{REFERENCES}

Abu Mustafa, N. (2008). Attitudes of psychological counselling students towards their specialization (A field study on a sample of students of psychological counselling specialization in the faculty of education at Al Aqsa University). Journal of Humanities Research, 16/2, $411-444$.

AL-Amarat,M.,\& AL-rfou, M .(2014). Correlation between the level of satisfaction with University life and the self - esteem among the female students at Tafila Technical University (TTU) in Jordan. The international interdisciplinary journal of education, 12: 266- 283.

Alawi, I. (2014). Self-esteem and mental health school. Any relationship? Journal of Education Sciences, 58: 30-43.

Al-Jarrah, A. (2007). Attitudes of counselling students at Yarmouk University toward their major in the light of some variables, Jordan Journal of Educational Sciences, 3/2, 165-181.

AL Nabhan, M. (2001). Developing a students' satisfaction level of studying at the Faculty of Education of Mu'tah University, Journal of the Educational Research Center, Qatar University. 10/20, 125-152.

Al-Ulwan, B. (2015). Self-esteem and its relationship to aggressive behavior among Jordanian university students, a comparison study between practitioners and nonpractitioners of sports activity. Journal of Sports Science, 22: 1-19.

Alwan, I. (2007). How does your son choose his specialty? Al-Riyadh newspaper, No. 14260.

Awwad, A. \& Ali, A. (2001).Satisfaction with the academic specialization and its relation to the social readiness of female students of the Faculty of Nursing - 8th Annual Conference of Psychological Counselling Center. Ain-Shams University, 537-568.

Coffman, D.\&Gilligan, T. (2003) Social support, stress, and self-efficacy: Effects on students' satisfaction. Journal of College Student Retention, 4/1, 53-66.

Deeb, F. (2014). The importance of self-esteem in the life of the human. Journal of Humanities and Social Sciences, 17: 17-24.

Hasan, T. (2016). Self-esteem and relation to anxiety in a sample of students of the faculty of education, University of Sudan, Journal of Educational Sciences, Sudan University of Science and Technology, 17 /1, 20-33.

Hanny, Kh. (2015). Quality of life and its relation to satisfaction with the academic majority of the university Student, (Unpublished Master Thesis). University of Hama Lakhdar Wadi. 
Jassim, Kh, \& Heliw, A. (2014). The desire of specialization and its relation to selfacademic motivation among university Students, Journal of Arts, University of Baghdad, 109: 609-640.

Kazem, A \& Al-Mia'mari, Kh. (2004). Sultan Qaboos University students' attitudes toward psychology, Journal of Educational and Psychological Sciences, University of Bahrain, 5/1, 9-35

Khaza'leh, A \& Tashtoush, R. (2011). Attitudes of students of special education in Qassim University towards their academic specialization in the light of some variables, Journal of the Arabian Gulf, 122: 101 - 135.

Lent, R.;, Brown,S., \& Hackett, G . (1994).Toward a unifying social cognitive theory of career and academic interest. Choice, and performance, Journal of Vocational Behavior. 45/1, 79-122.

Lent, R. (2004). Toward a unifying theoretical and practical perspective on well- being and psychological adjustment. Journal of Counselling Psychology, 51: 482-509.

McDonough P. M. (1994). Buying and selling higher education: The social construction of the college applicant. Journal of Higher Education. 65 /4, 427- 446.

Meesa, F. (2014). Satisfaction with the academic specialization and its relation to the level of ambition of the university student, (Unpublished master thesis). Alwadi University.

Miskiniene, M. \& Rodzeviciute, E. (2005). What motivates students to choose the teachers' profession: A scientific educology of university students? International Journal of Educology, Lithuanian. Spec, Iss: 38-50.

Murk, C. (1999). Self esteem: Research, theory and practice. $2^{\text {nd }}$ ed. Springer Publishing Company: New York.

Wildman, M. \& Torres, R. (2001). "Factors identified when selecting a major in agriculture. Journal of Agricultural Education, 42 /2, 46-55.

Williams, B.E. (2007). What influences undergraduate students to choose social worker. master of social work, A Thesis presented to the department of Social Worker, California State University, Long Beach.

Zhang, W. (2007). Why is: Understanding undergraduate students' intentions to choose an information systems major. Journal of Information Systems Education, 18/ 4, 447458.

Zayed, K. (2004). Self-esteem of the students of the physical education department at Sultan Qaboos University and its relation to the level of academic achievement, Journal of Jordanian University Studies, Special Iss: 321-333. 